\title{
Two Multi-Center Studies Evaluating Locally Delivered Doxycycline Hyclate, Placebo Control, Oral Hygiene, and Scaling and Root Planing in the Treatment of Periodontitis
}

Steven Garrett, ${ }^{*}$ Lonnie Johnson, ${ }^{\dagger}$ Connie Hastings Drisko, ${ }^{\ddagger}$ Donald F. Adams, $₫$ Carl Bandt, ${ }^{\circ}$ Bradley Beiswanger, "l Gary Bogle, ${ }^{\#}$ Kevin Donly, ${ }^{* *}$ William W. Hallmon, ${ }^{\dagger \dagger}$ E. Brady Hancock, ${ }^{\ddagger}$ Philip Hanes, $\$ \S$ Charles E. Hawley," "I Robert Kiger, "Tी William Killoy," ${ }^{\# \# ~ J a m e s ~ T . ~ M e l l o n i g, ~}{ }^{* * *}$ Alan Polson, ${ }^{\dagger \dagger}$ Frank J. Raab, $\$$ Mark Ryder, ${ }^{\ddagger \ddagger}$ Norman H. Stoller, ${ }^{\dagger}$ Hom-Lay Wang, $§ \S \S$ Lawrence E. Wolinsky, ${ }^{\prime \prime}$ II II Gerald H. Evans, Charles Q. Harrold, ${ }^{\dagger}$ Ralph M. Arnold, ${ }^{\# \# \# ~ D a v i d ~ F . ~ A t a c k, ~} §$ Bryan Fitzgerald,,$" \|$ Margaret Hill, ${ }^{\ddagger}$ Roger L.

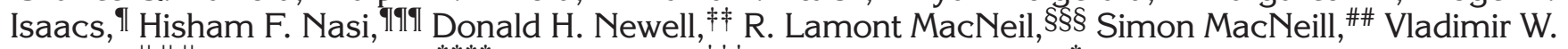
Spolsky, "I II Susan P. Duke, ${ }^{* * * *}$ Anne Polson, ${ }^{\dagger \dagger \dagger}$ and G. Lee Southard*

Background: The clinical efficacy and safety of doxycycline hyclate $(8.5 \% \mathrm{w} / \mathrm{w})$ delivered subgingivally in a biodegradable polymer $(\mathrm{DH})$ was compared to placebo control $(\mathrm{VC})$, oral hygiene $(\mathrm{OH})$, and scaling and root planing (SRP) in 2 multi-center studies.

Methods: Each study entered 411 patients who demonstrated moderate to severe periodontitis. Patients had 2 or more quadrants each with a minimum of 4 qualifying pockets $\geq 5 \mathrm{~mm}$ that bled on probing. At least 2 of the pockets were $\geq 7 \mathrm{~mm}$. Treatment with $\mathrm{DH}, \mathrm{VC}, \mathrm{OH}$, or SRP was provided at baseline and again at month 4 . Clinical parameters were recorded monthly.

Results: DH and SRP resulted in nearly identical clinical changes over time in both studies. Mean 9 month clinical attachment level gain (ALG) was $0.8 \mathrm{~mm}$ for the DH group and $0.7 \mathrm{~mm}$ for the SRP group in Study 1, and $0.8 \mathrm{~mm}(\mathrm{DH})$ and $0.9 \mathrm{~mm}$ (SRP) in Study 2. Mean probing depth (PD) reduction was $1.1 \mathrm{~mm}$ for the DH group and $0.9 \mathrm{~mm}$ for the SRP group in Study 1 and $1.3 \mathrm{~mm}$ for both groups in Study 2. Frequency distributions showed an ALG $\geq 2 \mathrm{~mm}$ in $29 \%$ of DH sites versus $27 \%$ of SRP sites in Study 1 and $31 \%$ of DH sites versus $34 \%$ of SRP sites in Study 2. PD reductions $\geq 2 \mathrm{~mm}$ were seen in $32 \%$ of DH sites versus $31 \%$ of SRP sites in Study 1 and $41 \%$ of DH sites versus $43 \%$ of SRP sites in Study 2. Comparisons between DH, VC, and OH treatment groups showed DH treatment to be statistically superior to $\mathrm{VC}$ and $\mathrm{OH}$. Safety data demonstrated a benign safety profile with use of the DH product.

Conclusions: Results of this trial demonstrate that treatment of periodontitis with subgingivally delivered doxycycline in a biodegradable polymer is equally effective as scaling and root planing and superior in effect to placebo control and oral hygiene in reducing the clinical signs of adult periodontitis over a 9-month period. This represents positive changes resulting from the use of subgingivally applied doxycycline as scaling and root planing was not limited regarding time of the procedure or use of local anesthesia. J Periodontol 1999;70:490-503.

\section{KEYWORDS}

Drug delivery systems; doxycycline/therapeutic use; periodontitis/drug therapy; multi-center studies.

\footnotetext{
* Atrix Laboratories, Inc., Fort Collins, CO.

$\dagger$ University of Colorado, Denver, CO.

‡ University of Louisville, Louisville, KY.

$\S$ Oregon Health Sciences University, Portland, OR.

II University of Minnesota, Minneapolis, MN.

I Oral Health Research Institute, Indianapolis, IN.

\# Loma Linda University, Loma Linda, CA.

** University of lowa, lowa City, IA.

$\dagger \dagger$ Baylor College of Dentistry, Dallas, TX.

$\neq \neq$ Indiana University, Indianapolis, IN.

$\S \S$ Medical College of Georgia, Augusta, GA.

II II University of Maryland, Baltimore, MD.

II Currently, Loma Linda University, Loma Linda, CA; previously, Jerry L. Pettis VAH, Loma Linda, CA.
}

\footnotetext{
\#\# University of Missouri, Kansas City, MO

*** University of Texas, San Antonio, TX.

$\dagger \dagger \dagger$ University of Pennsylvania, Philadelphia, PA.

俦 University of California, San Francisco, CA.

$\S \S \S \quad$ University of Michigan, Ann Arbor, MI.

II II I| UCLA School of Dentistry, Los Angeles, CA.

III Louisiana State University, New Orleans, LA.

\#\#\# Currently Family Medical/Dental Center, Anchorage, AK; previously, University of Texas, San Antonio, TX.

**** Currently, Glaxo Wellcome, Inc., Research Triangle Park, NC; previously, Atrix Laboratories, Inc., Fort Collins, CO.
} 
$\mathrm{T}$ The elimination or alteration of the microbial pathogens present in subgingival plaque is the primary object of periodontal therapy. Complications from the inflammatory lesion resulting from this infection lead to progressive destruction of the supporting periodontal attachment apparatus in susceptible hosts. The microbial factors ${ }^{1}$ associated with periodontal diseases, as well as their pathogenesis, ${ }^{2}$ have been recently reviewed. One essential goal of current periodontitis therapy is successful management of the suspected bacterial pathogens to the extent that destruction of the periodontium is arrested. A number of different non-surgical and surgical therapies have been successful in achieving this goal. ${ }^{3-6}$ The primary non-surgical approach involves mechanical scaling and root planing (SRP). ${ }^{3}$

Another less invasive approach is to control the suspected bacterial pathogens by administering an antimicrobial agent into the periodontal pocket. With this type of treatment, delivery systems that are biodegradable and provide controlled release of the antimicrobial agent seem ideal. They provide appropriate antimicrobial levels for sustained periods without frequent applications or need for removal at some future timepoint. ${ }^{7-9}$ Many different delivery systems containing various antimicrobial agents have been, and are being, developed as non-mechanical therapies for periodontitis. They are used either adjunctively or independently of mechanical treatments as monotherapy. ${ }^{10}$

The 2 studies reported in this paper were designed to test the safety and effectiveness of doxycycline hyclate delivered subgingivally to human periodontal pockets in a biodegradable controlled-release delivery system. Animal results ${ }^{11}$ and a large multi-center human clinical trial ${ }^{12}$ have shown favorable responses following use of this treatment for periodontitis. The studies reported in this paper are the basis for the clinical portion of a New Drug Application with the U.S. Food and Drug Administration for acceptance of this product to treat human periodontitis.

\section{MATERIALS AND METHODS}

\section{Study Design}

These two 9-month, multi-center studies used randomized, parallel, single-blind designs and compared results of 1) subgingivally administered doxycycline hyclate $(\mathrm{DH})$; 2) vehicle control (VC); 3) oral hygiene (OH); and 4) scaling and root planing (SRP). In each study (10 research centers per study; 6 to 15 subjects per group at each center), 411 patients were entered of whom 375 completed Study 1 and 383 Study 2 . Subjects were excluded from participation in the study if they were using any contraindicated medications, presented with compromising medical conditions, or had been treated with SRP within 2 months of the baseline treatment visit. The elements of the studies have been discussed in detail in a previous research report. ${ }^{13}$ Both were carried out in an identical manner and were conducted in compliance with FDA Good Clinical Practice Guidelines, institutional review board (IRB) requirements, ${ }^{14}$ and informed consent requirements. ${ }^{15}$ The protocols and informed consent were approved by the appropriate human subjects review committees and reviewed by the FDA. A brief summary of the study design is provided below.

\section{Subject Eligibility}

Eligibility was determined at a screening examination. Subjects were included if they gave informed consent, were 25 to 75 years of age, and had generalized moderate to severe periodontitis in at least 2 quadrants. To qualify, each of the 2 quadrants had to contain a minimum of 4 periodontal pocket sites $\geq 5 \mathrm{~mm}$ that bled on probing. Two of the qualifying sites were required to have a probing depth $\geq 7 \mathrm{~mm}$. Other details of the exclusion/inclusion criteria have been published previously. ${ }^{13}$ Each subject was randomized to 1 of 4 treatment groups: 1) doxycycline hyclate $(\mathrm{DH}) ; 2$ ) vehicle control (VC); 3) oral hygiene (OH); and 4) scaling and root planing (SRP). Each subject received only one treatment in this parallel design study.

\section{Treatment Procedures}

The formulation containing doxycycline hyclate (DH) was a solution containing $8.5 \%$ weight to weight doxycycline hyclate, $37 \%$ weight to weight poly(DL-lactide) (PLA) dissolved in a biocompatible carrier of $63 \%$ weight to weight N-methyl-2-pyrrolidone (NMP)..$^{\dagger \dagger \dagger}$ In the case of $\mathrm{DH}$, the 2 components of the formulation (vehicle and doxycycline hyclate) were provided in 2 separate syringes that were coupled together just prior to use and mixed for 100 cycles. Once mixed, the DH was allowed to sit at room temperature for 15 minutes and then mixed for another 10 cycles before use. A 23gauge cannula was attached to the delivery syringe and the DH was expressed into the periodontal pocket. Any overflow material was gently packed into the pocket with a moist curet. Qualifying sites in 2 quadrants were treated.

The vehicle control (VC) was a solution containing $37 \%$ weight to weight PLA in $63 \%$ weight-to-weight NMP. It was provided in a single syringe and applied to qualifying sites as previously described for $\mathrm{DH}$.

Quadrants treated with DH and VC were covered

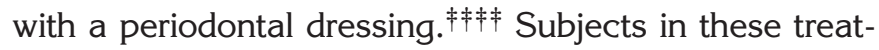
ment groups returned at day 7 for removal of the dressing and test material (subsequent studies have shown that removal of $\mathrm{DH}$ is unnecessary; unpublished data). $\mathrm{DH}$ and $\mathrm{VC}$ were applied to each qualifying pocket in 2 treated quadrants in subjects randomized to that

$\dagger \dagger \dagger \dagger$ Atridox, Block Drug Corporation, Inc., Jersey City, NJ.

㧊 Coe-Pak periodontal dressing, GC America, Inc., Chicago, IL. 
respective treatment group at baseline and month 4 visits. Subjects in these 2 treatment groups were instructed not to perform oral hygiene on the treated quadrants for 7 days following treatment. Untreated quadrants received no treatment other than oral hygiene during the study.

Subjects randomized to the oral hygiene group $(\mathrm{OH})$ were instructed in the Bass brushing technique, as well as the proper use of dental floss. They were instructed to brush and floss 2 times a day. Oral hygiene compliance was queried at each subsequent visit, and further instruction provided as necessary. Subjects receiving $\mathrm{DH}, \mathrm{VC}$, or SRP treatments also received oral hygiene instructions identical to those received by the subjects in the $\mathrm{OH}$ group.

Subjects randomized to receive SRP received a single episode of SRP in the 2 treated quadrants at baseline, repeated at month 4 . Therapists were instructed to continue the SRP until treated root surfaces felt hard and smooth to a dental explorer. Subjects were given local anesthesia on request. No time restraints were placed on the SRP therapist; instead, treatment proceeded until the therapist was entirely satisfied with the endpoint. SRP therapists were either periodontists or dental hygienists chosen by the principal investigator at each study center. The untreated quadrants did not receive mechanical instrumentation during the course of the study. Subjects were instructed to begin oral hygiene in the treated quadrants the day following SRP.

\section{Treatment Assignment and Blinding}

All subjects were randomized to treatment groups according to a computer-generated random code. These were single-blind studies, in that the examiners at each center were blinded to treatment. A doubleblind design was not possible because of the dissimilar treatments between various treatment groups.

\section{EVALUATIONS}

A schedule of the evaluation timepoints and data collection at each timepoint is outlined in Figure 1. Measurements of probing depth, bleeding on probing, clinical attachment level, and plaque index ${ }^{16-18}$ were made at these timepoints. Probing measurements were made at 6 location points on all teeth in the dentition using a periodontal probe ${ }^{\S \S \S \S}$ graduated in $1 \mathrm{~mm}$ increments with readings made to the nearest millimeter. Four or 5 sites in each of the quadrants that qualified for the study were selected for attachment level measurements using the cemento-enamel junction (CEJ), or other nearby landmark. Duplicate attachment level measurements were made at each attachment level site during each exam with approximately 20 minutes between the recordings. The average of these 2 recordings was used as the attachment level measurement for that site. Concomitant medications and safety evaluations were recorded at each visit. Any suspected adverse events or allergic responses were evaluated carefully by the investigator. Further details concerning these evaluation appointments have been published previously. ${ }^{13}$

\section{Pre-Study Training}

Details of the elements of the pre-study calibration and center training program have been previously described. ${ }^{13}$ In these studies, all examiners were calibrated to one gold standard examiner (author CQH). Calibration continued until examiners reached levels previously described. ${ }^{13}$ Study teams not involved in a previous multi-center study ${ }^{12}$ carried out a training study in which 4 to 10 subjects were entered, treated with $\mathrm{DH}$, and followed for 30 days. This was done under a separate protocol, and data from these subjects are not included in this report.

\section{Statistical Methods}

The studies were powered to show a $0.35 \mathrm{~mm}$ difference between treatment groups as significant. This required a sample size of approximately 100 subjects per treatment group at $80 \%$ power. The primary efficacy endpoints were mean change in attachment level and probing depth. Means were calculated using the sum of the treated site measurements for a subject divided by the number of treated sites. For all parameters, the subject mean was the basis of the statistical analysis, not the sites alone. ${ }^{19,20}$ Efficacy results for qualifying treated sites for attachment level and probing depth were analyzed statistically by analysis of variance (ANOVA) on differences from baseline values between groups. The null hypothesis was that there were no treatment group differences. All statistical tests were conducted at a significance level of $P \leq 0.05$. All tests were 2 -tailed.

Study procedures involving criteria for study monitoring, data management and exclusion of subjects, tooth sites, or investigators/centers have all been described previously ${ }^{13}$ and will not be reviewed in this report.

\section{RESULTS}

The efficacy parameters evaluated were mean change in attachment level and mean change in probing depth. ANOVA analyses are presented for data combined from all centers in each study for each parameter and treatment group. The number of subjects per group available for analysis varied at each analysis timepoint based on a blinded determination of whether they were efficacy-evaluable at that particular study timepoint. Plaque score changes are presented as well, as a measurement of compliance.

Clinical Attachment Level Gain (ALG) - Mean Data

Study 1. Mean ALG for all subjects is represented in Table 1. All treatment groups showed improvement

§§§§ UNC \#15, Hu-Friedy, Chicago, IL. 


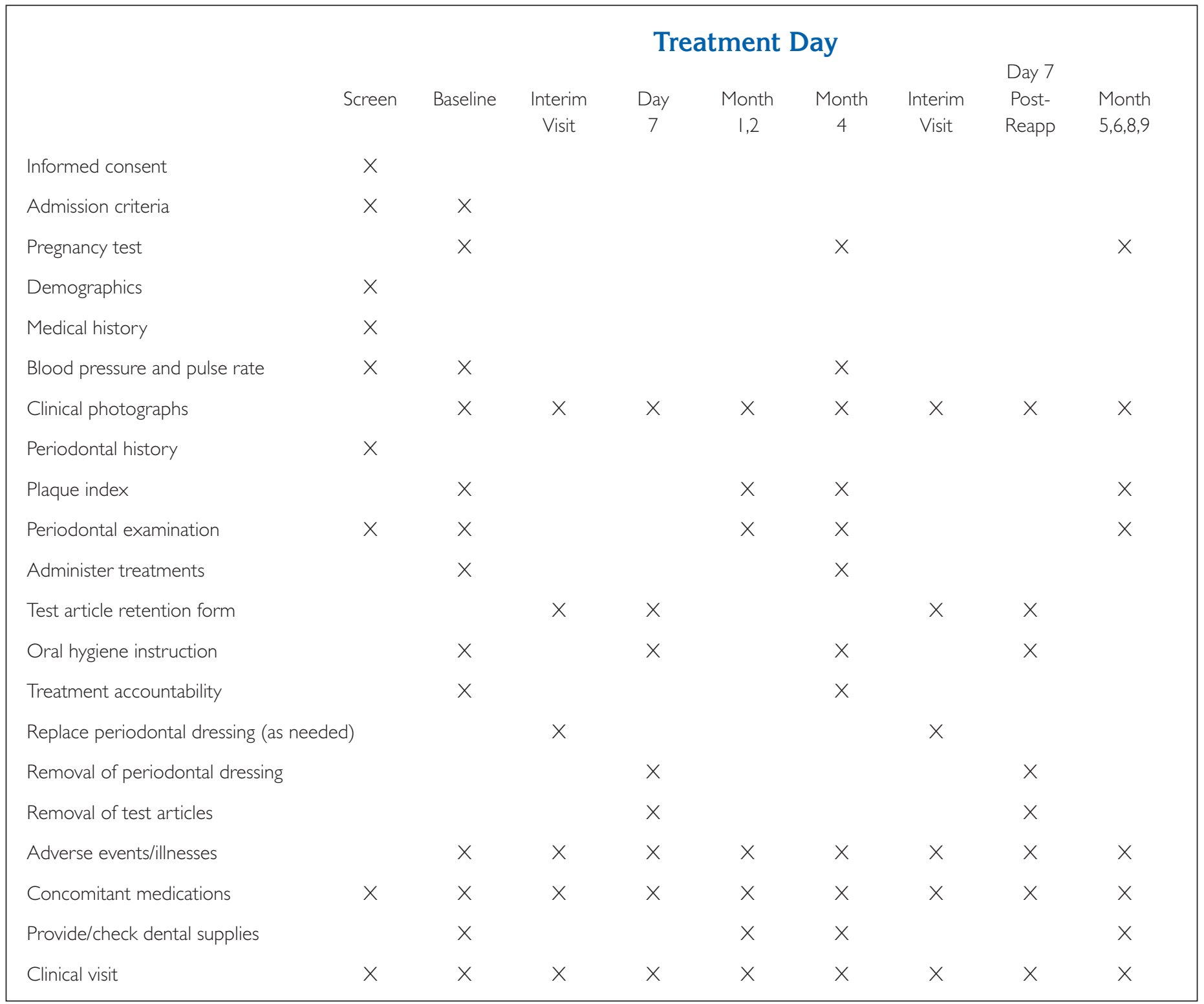

\section{Figure I.}

Schematic outline of study procedures.

from baseline in ALG. The majority of the gain occurred at month 1 and was generally sustained through month 4. Re-treatment at month 4 resulted in a small incremental gain in the DH and SRP groups which was maintained through month 9. No additional improvement was observed in the $\mathrm{VC}$ and $\mathrm{OH}$ groups. The VC group lost most of the initial gain as the study approached month 9. Results in the DH group were statistically significant $(P \leq 0.05)$ when compared with the $\mathrm{VC}$ and $\mathrm{OH}$ groups after month 1 . DH and SRP results were nearly identical over time. The mean ALG at month 9 was $0.8 \mathrm{~mm}$ in the DH group and $0.7 \mathrm{~mm}$ in the SRP group.

Study 2. Mean ALG in Study 2 followed a similar pattern to Study 1. Again, the majority of the change occurred by month 1 with additional improvement at month 4 in the DH and SRP groups. Results in the DH group were statistically significant $(P \leq 0.05)$ when compared with $\mathrm{VC}$ and $\mathrm{OH}$ after month 1. DH and SRP results were nearly identical over time with mean ALG of $0.8 \mathrm{~mm}$ and $0.9 \mathrm{~mm}$ for the DH and SRP groups, respectively, at month 9 . In this study, the initial VC benefit was maintained throughout the study. The oral hygiene effect was consistently somewhat stronger than that observed in Study 1.

\section{Probing Depth Reduction (PD) - Mean Data}

Study 1. Mean PD reduction for all subjects is presented in Table 2. As with ALG, most of the improvement was noted at month 1 , with incremental benefits following the month 4 re-treatment in the DH and SRP groups. No additional benefit was observed in the other 
Table I.

\section{Gain in Attachment Level (mm)}

\begin{tabular}{|c|c|c|c|c|c|c|c|c|}
\hline & Baseline & Month I & Month 2 & Month 4 & Month 5 & Month 6 & Month 8 & Month 9 \\
\hline \multicolumn{9}{|l|}{ Study 1} \\
\hline \multicolumn{9}{|l|}{$\mathrm{DH}$} \\
\hline$N$ & 95 & 79 & 75 & 75 & 75 & 72 & 73 & 80 \\
\hline Mean (s.e.) & $6.1(0.2)$ & $0.6(0.1)$ & $0.7(0.1)$ & $0.6(0.1)$ & $0.7(0.1)$ & $0.8(0.1)$ & $0.8(0.1)$ & $0.8(0.1)$ \\
\hline \multicolumn{9}{|l|}{ VC } \\
\hline$N$ & 94 & 85 & 78 & 82 & 76 & 79 & 78 & 82 \\
\hline Mean (s.e.) & $6.1(0.2)$ & $0.4(0.1)$ & $0.4(0.1)$ & $0.3(0.1)$ & $0.3(0.1)$ & $0.1(0.1)$ & $0.1(0.1)$ & $0.1(0.1)$ \\
\hline \multicolumn{9}{|l|}{$\mathrm{OH}$} \\
\hline N & 95 & 86 & 81 & 78 & 74 & 77 & 78 & 83 \\
\hline Mean (s.e.) & $6.2(0.2)$ & $0.5(0.1)$ & $0.3(0.1)$ & $0.4(0.1)$ & $0.3(0.1)$ & $0.3(0.1)$ & $0.4(0.1)$ & $0.3(0.1)$ \\
\hline \multicolumn{9}{|l|}{ SRP } \\
\hline N & 99 & 80 & 88 & 91 & 80 & 80 & 86 & 84 \\
\hline Mean (s.e.) & $5.8(0.2)$ & $0.6(0.1)$ & $0.6(0.1)$ & $0.6(0.1)$ & $0.6(0.1)$ & $0.7(0.1)$ & $0.7(0.1)$ & $0.7(0.1)$ \\
\hline \multicolumn{9}{|l|}{$P$ value } \\
\hline DH vs.VC & & 0.062 & 0.001 & 0.028 & 0.008 & $<0.001$ & $<0.001$ & $<0.001$ \\
\hline $\mathrm{DH}$ vs. $\mathrm{OH}$ & & 0.206 & 0.002 & 0.051 & 0.015 & 0.002 & 0.005 & 0.001 \\
\hline DH vs. SRP & & 0.615 & 0.175 & 0.680 & 0.569 & 0.510 & 0.728 & 0.294 \\
\hline \multicolumn{9}{|l|}{ Study 2} \\
\hline \multicolumn{9}{|l|}{$\mathrm{DH}$} \\
\hline N & 96 & 86 & 84 & 88 & 79 & 80 & 84 & 85 \\
\hline Mean (s.e.) & $5.6(0.2)$ & $0.6(0.1)$ & $0.6(0.1)$ & $0.7(0.1)$ & $0.8(0.1)$ & $0.8(0.1)$ & $0.9(0.1)$ & $0.8(0.1)$ \\
\hline \multicolumn{9}{|l|}{ VC } \\
\hline$N$ & 96 & 89 & 87 & 81 & 81 & 81 & 79 & 83 \\
\hline Mean (s.e.) & $5.9(0.2)$ & $0.4(0.1)$ & $0.3(0.1)$ & $0.4(0.1)$ & $0.4(0.1)$ & $0.4(0.1)$ & $0.4(0.1)$ & $0.5(0.1)$ \\
\hline \multicolumn{9}{|l|}{$\mathrm{OH}$} \\
\hline$N$ & 94 & 85 & 86 & 89 & 89 & 88 & 85 & 89 \\
\hline Mean (s.e.) & $6.0(0.2)$ & $0.4(0.1)$ & $0.4(0.1)$ & $0.5(0.1)$ & $0.5(0.1)$ & $0.5(0.1)$ & $0.5(0.1)$ & $0.5(0.1)$ \\
\hline \multicolumn{9}{|l|}{ SRP } \\
\hline $\mathrm{N}$ & 103 & 90 & 91 & 90 & 86 & 90 & 97 & 98 \\
\hline Mean (s.e.) & $5.7(0.2)$ & $0.6(0.1)$ & $0.6(0.1)$ & $0.6(0.1)$ & $0.7(0.1)$ & $0.7(0.1)$ & $0.8(0.1)$ & $0.9(0.1)$ \\
\hline \multicolumn{9}{|l|}{$P$ value } \\
\hline DH vs.VC & & 0.056 & 0.002 & 0.003 & $<0.001$ & 0.003 & $<0.001$ & 0.002 \\
\hline DH vs. OH & & 0.074 & 0.048 & 0.056 & 0.008 & 0.026 & 0.001 & 0.012 \\
\hline DH vs. SRP & & 0.662 & 0.847 & 0.783 & 0.226 & 0.313 & 0.603 & 0.665 \\
\hline
\end{tabular}

treatment groups. As with ALG, DH results were generally statistically superior $(P \leq 0.05)$ to $\mathrm{VC}$ and $\mathrm{OH}$ groups beginning at month 1 . Again, results in the DH and SRP groups were nearly identical over time, although the DH group was statistically superior $(P \leq 0.05)$ at month 9 (DH reduction $1.1 \mathrm{~mm}$; SRP reduction $0.9 \mathrm{~mm}$ ). Unlike ALG, the VC group generally showed somewhat more $\mathrm{PD}$ reduction than the $\mathrm{OH}$ group.
Study 2. Mean PD reduction in Study 2 was similar to that in Study 1, with the DH group results superior $(P \leq 0.05)$ to $\mathrm{VC}$ and $\mathrm{OH}$ beginning at month 1 . Again there was incremental benefit to the re-treatment at month 4 in the DH and SRP groups. Results between these groups were nearly identical $(1.3 \mathrm{~mm}$ reduction in both groups at month 9), as were results between the $\mathrm{VC}$ and $\mathrm{OH}$ groups. As with ALG, the $\mathrm{OH}$ 


\section{Table 2.}

\section{Reduction in Probing Depth ( $\mathrm{mm}$ )}

\begin{tabular}{|c|c|c|c|c|c|c|c|c|}
\hline & Baseline & Month I & Month 2 & Month 4 & Month 5 & Month 6 & Month 8 & Month 9 \\
\hline \multicolumn{9}{|l|}{ Study 1} \\
\hline \multicolumn{9}{|l|}{$\mathrm{DH}$} \\
\hline$N$ & 95 & 79 & 75 & 75 & 75 & 72 & 73 & 80 \\
\hline Mean (s.e.) & $6.0(<0.1)$ & $0.9(0.1)$ & $0.9(0.1)$ & $0.9(0.1)$ & I.I (0.1) & I.I (0.1) & I.I (0.1) & $1.1(0.1)$ \\
\hline \multicolumn{9}{|l|}{ VC } \\
\hline N & 94 & 85 & 78 & 82 & 76 & 79 & 78 & 82 \\
\hline Mean (s.e.) & $5.9(<0.1)$ & $0.7(0.1)$ & $0.7(0.1)$ & $0.8(0.1)$ & $0.8(0.1)$ & $0.8(0.1)$ & $0.7(0.1)$ & $0.8(0.1)$ \\
\hline \multicolumn{9}{|l|}{$\mathrm{OH}$} \\
\hline N & 95 & 86 & 81 & 78 & 74 & 77 & 78 & 83 \\
\hline Mean (s.e.) & $6.0(<0.1)$ & $0.6(0.1)$ & $0.6(0.1)$ & $0.6(0.1)$ & $0.5(0.1)$ & $0.5(0.1)$ & $0.5(0.1)$ & $0.5(0.1)$ \\
\hline \multicolumn{9}{|l|}{ SRP } \\
\hline$N$ & 99 & 80 & 88 & 91 & 80 & 80 & 86 & 84 \\
\hline Mean (s.e.) & $5.9(<0.1)$ & $0.9(0.1)$ & $0.9(0.1)$ & $0.9(0.1)$ & I.I (0.1) & I.I (0.1) & $1.0(0.1)$ & $0.9(0.1)$ \\
\hline \multicolumn{9}{|l|}{$P$ value } \\
\hline DH vs. VC & & 0.010 & 0.018 & 0.096 & 0.004 & 0.015 & $<0.001$ & 0.001 \\
\hline $\mathrm{DH}$ vs. $\mathrm{OH}$ & & 0.003 & $<0.001$ & $<0.001$ & $<0.001$ & $<0.001$ & $<0.001$ & $<0.001$ \\
\hline DH vs. SRP & & 0.954 & 0.877 & 0.624 & 0.994 & 0.900 & 0.337 & 0.050 \\
\hline \multicolumn{9}{|l|}{ Study 2} \\
\hline \multicolumn{9}{|l|}{$\mathrm{DH}$} \\
\hline$N$ & 96 & 86 & 84 & 88 & 79 & 80 & 84 & 85 \\
\hline Mean (s.e.) & $5.9(<0.1)$ & $1.0(0.1)$ & $1.0(0.1)$ & $1.0(0.1)$ & $1.2(0.1)$ & $1.3(0.1)$ & $1.3(0.1)$ & $1.3(0.1)$ \\
\hline \multicolumn{9}{|l|}{ VC } \\
\hline$N$ & 96 & 89 & 87 & 81 & 81 & 81 & 79 & 83 \\
\hline Mean (s.e.) & $6.0(0.1)$ & $0.6(<0.1)$ & $0.6(0.1)$ & $0.7(0.1)$ & $0.9(0.1)$ & $0.9(0.1)$ & $0.9(0.1)$ & $1.0(0.1)$ \\
\hline \multicolumn{9}{|l|}{$\mathrm{OH}$} \\
\hline$N$ & 94 & 85 & 86 & 89 & 89 & 88 & 85 & 89 \\
\hline Mean (s.e.) & $5.9(0.1)$ & $0.6(<0.1)$ & $0.7(0.1)$ & $0.7(0.1)$ & $0.8(0.1)$ & $0.9(0.1)$ & $0.9(0.1)$ & $0.9(0.1)$ \\
\hline \multicolumn{9}{|l|}{ SRP } \\
\hline$N$ & 103 & 90 & 91 & 90 & 86 & 90 & 97 & 98 \\
\hline Mean (s.e.) & $5.9(<0.1)$ & $1.0(<0.1)$ & $1.1(0.1)$ & I.I (0.1) & $1.3(0.1)$ & $1.3(0.1)$ & $1.3(0.1)$ & $1.3(0.1)$ \\
\hline \multicolumn{9}{|l|}{$P$ value } \\
\hline DH vs. VC & & $<0.001$ & $<0.001$ & $<0.001$ & $<0.001$ & $<0.001$ & $<0.001$ & 0.001 \\
\hline $\mathrm{DH}$ vs. $\mathrm{OH}$ & & $<0.001$ & $<0.001$ & 0.002 & $<0.001$ & $<0.001$ & $<0.001$ & $<0.001$ \\
\hline DH vs. SRP & & 0.322 & 0.279 & 0.642 & 0.505 & 0.988 & 0.865 & 0.765 \\
\hline
\end{tabular}

response was greater in Study 2 than in Study 1.

\section{ALG and PD Reduction in Moderate Sites (Initial PD 5 to $6 \mathrm{~mm}$ )}

Table 3 presents ALG for sites with moderate probing depths at baseline. In Study 1, the DH treatment group is statistically superior to $\mathrm{VC}$ and $\mathrm{OH}$ beginning at month 1 and to SRP at months 6 through 9. There is lit- tle additional benefit to the second treatment at month 4 in any of the treatment groups. At month 9, there is little benefit observed in the VC and OH groups, and the ALG of the DH group is double that of the SRP group $(0.6 \mathrm{~mm}$ versus $0.3 \mathrm{~mm})$. In Study 2 there are no differences between the DH and SRP groups. Changes in these groups are generally double the changes in the VC and $\mathrm{OH}$ groups, with $\mathrm{DH}$ superior to $\mathrm{VC}$ beginning at 


\section{Table 3.}

\section{Gain in Attachment Level (mm) for Initial Probing Depths of 5 to $6 \mathrm{~mm}$}

\begin{tabular}{|c|c|c|c|c|c|c|c|c|}
\hline & Baseline & Month I & Month 2 & Month 4 & Month 5 & Month 6 & Month 8 & Month 9 \\
\hline \multicolumn{9}{|l|}{ Study 1} \\
\hline \multicolumn{9}{|l|}{$\mathrm{DH}$} \\
\hline N & 93 & 77 & 74 & 73 & 73 & 70 & 71 & 78 \\
\hline Mean (s.e.) & $5.3(0.2)$ & $0.5(0.1)$ & $0.6(0.1)$ & $0.5(0.1)$ & $0.6(0.1)$ & $0.7(0.1)$ & $0.6(0.1)$ & $0.6(0.1)$ \\
\hline \multicolumn{9}{|l|}{ VC } \\
\hline N & 94 & 85 & 78 & 82 & 76 & 79 & 78 & 82 \\
\hline Mean (s.e.) & $5.2(0.2)$ & $0.3(0.1)$ & $0.1(0.1)$ & $0.1(0.1)$ & $0.1(0.1)$ & $0.0(0.1)$ & $0.1(0.1)$ & $0.1(0.1)$ \\
\hline \multicolumn{9}{|l|}{$\mathrm{OH}$} \\
\hline$N$ & 94 & 85 & 80 & 77 & 73 & 76 & 77 & 82 \\
\hline Mean (s.e.) & $5.5(0.2)$ & $0.3(0.1)$ & $0.1(0.1)$ & $0.1(0.1)$ & $0.1(0.1)$ & $0.2(0.1)$ & $0.2(0.1)$ & $0.1(0.1)$ \\
\hline \multicolumn{9}{|l|}{ SRP } \\
\hline $\mathrm{N}$ & 98 & 79 & 87 & 91 & 79 & 80 & 85 & 84 \\
\hline Mean (s.e.) & $5.0(0.2)$ & $0.3(0.1)$ & $0.3(0.1)$ & $0.3(0.1)$ & $0.3(0.1)$ & $0.3(0.1)$ & $0.3(0.1)$ & $0.3(0.1)$ \\
\hline \multicolumn{9}{|l|}{$P$ value } \\
\hline DH vs. VC & & 0.079 & 0.002 & 0.001 & $<0.001$ & $<0.001$ & $<0.001$ & $<0.001$ \\
\hline $\mathrm{DH}$ vs. $\mathrm{OH}$ & & 0.052 & 0.001 & 0.002 & 0.001 & 0.002 & 0.002 & $<0.001$ \\
\hline DH vs. SRP & & 0.060 & 0.073 & 0.078 & 0.057 & 0.018 & 0.015 & 0.022 \\
\hline \multicolumn{9}{|l|}{ Study 2} \\
\hline \multicolumn{9}{|l|}{$\mathrm{DH}$} \\
\hline N & 95 & 85 & 83 & 87 & 78 & 79 & 83 & 84 \\
\hline Mean (s.e.) & $4.9(0.2)$ & $0.4(0.1)$ & $0.5(0.1)$ & $0.6(0.1)$ & $0.7(0.1)$ & $0.7(0.1)$ & $0.8(0.1)$ & $0.7(0.1)$ \\
\hline \multicolumn{9}{|l|}{ VC } \\
\hline N & 94 & 87 & 85 & 80 & 80 & 80 & 78 & 82 \\
\hline Mean (s.e.) & $5.1(0.2)$ & $0.3(0.1)$ & $0.2(0.1)$ & $0.3(0.1)$ & $0.3(0.1)$ & $0.3(0.1)$ & $0.3(0.1)$ & $0.3(0.1)$ \\
\hline \multicolumn{9}{|l|}{$\mathrm{OH}$} \\
\hline N & 93 & 84 & 85 & 88 & 88 & 87 & 84 & 88 \\
\hline Mean (s.e.) & $5.4(0.2)$ & $0.3(0.1)$ & $0.3(0.1)$ & $0.3(0.1)$ & $0.4(0.1)$ & $0.4(0.1)$ & $0.4(0.1)$ & $0.4(0.1)$ \\
\hline \multicolumn{9}{|l|}{ SRP } \\
\hline N & 103 & 90 & 91 & 90 & 86 & 90 & 97 & 98 \\
\hline Mean (s.e.) & $5.1(0.2)$ & $0.4(0.1)$ & $0.5(0.1)$ & $0.6(0.1)$ & $0.6(0.1)$ & $0.6(0.1)$ & $0.7(0.1)$ & $0.7(0.1)$ \\
\hline \multicolumn{9}{|l|}{$P$ value } \\
\hline DH vs. VC & & 0.110 & 0.004 & 0.003 & $<0.00 \mid$ & 0.002 & $<0.001$ & $<0.001$ \\
\hline $\mathrm{DH}$ vs. $\mathrm{OH}$ & & 0.140 & 0.095 & 0.014 & 0.036 & 0.018 & 0.004 & 0.003 \\
\hline DH vs. SRP & & 0.987 & 0.962 & 0.834 & 0.643 & 0.736 & 0.698 & 0.738 \\
\hline
\end{tabular}

month 2, and to $\mathrm{OH}$ beginning at month 3 throughout the remainder of the study. At month 9, ALG for both the DH and SRP groups was $0.7 \mathrm{~mm}$.

Table 4 presents PD reductions for moderately deep sites. In both studies, PD reduction is very similar between the DH and SRP groups. Again, at all timepoints in both studies beginning at month 1 , the $\mathrm{DH}$ group is superior to the $\mathrm{VC}$ and $\mathrm{OH}$ groups. Month 9 reductions in the $\mathrm{DH}$ group were statistically superior to the SRP group in Study $1(0.9 \mathrm{~mm}$ versus $0.7 \mathrm{~mm})$. Both DH and SRP showed a $1.1 \mathrm{~mm}$ reduction at month 9 in Study 2. In Study 1, PD reduction was somewhat better in the VC group than the $\mathrm{OH}$ group. In Study 2 , results were very similar. 


\section{Table 4.}

\section{Reduction in Probing Depth (mm) for Initial Probing Depths of 5 to $6 \mathrm{~mm}$}

\begin{tabular}{|c|c|c|c|c|c|c|c|c|}
\hline & Baseline & Month I & Month 2 & Month 4 & Month 5 & Month 6 & Month 8 & Month 9 \\
\hline \multicolumn{9}{|l|}{ Study 1} \\
\hline \multicolumn{9}{|l|}{$\mathrm{DH}$} \\
\hline$N$ & 95 & 79 & 75 & 75 & 75 & 72 & 73 & 80 \\
\hline Mean (s.e.) & $5.3(<0.1)$ & $0.7(0.1)$ & $0.8(0.1)$ & $0.7(0.1)$ & $1.0(0.1)$ & $0.9(0.1)$ & $0.9(0.1)$ & $0.9(0.1)$ \\
\hline \multicolumn{9}{|l|}{ VC } \\
\hline N & 94 & 85 & 78 & 82 & 76 & 79 & 78 & 82 \\
\hline Mean (s.e.) & $5.3(<0.1)$ & $0.5(0.1)$ & $0.6(0.1)$ & $0.5(0.1)$ & $0.7(0.1)$ & $0.6(0.1)$ & $0.5(0.1)$ & $0.6(0.1)$ \\
\hline \multicolumn{9}{|l|}{$\mathrm{OH}$} \\
\hline$N$ & 95 & 86 & 81 & 78 & 74 & 77 & 78 & 83 \\
\hline Mean (s.e.) & $5.3(<0.1)$ & $0.4(0.1)$ & $0.4(0.1)$ & $0.3(0.1)$ & $0.3(0.1)$ & $0.3(0.1)$ & $0.3(0.1)$ & $0.3(0.1)$ \\
\hline \multicolumn{9}{|l|}{ SRP } \\
\hline N & 99 & 80 & 88 & 91 & 80 & 80 & 86 & 84 \\
\hline Mean (s.e.) & $5.3(<0.1)$ & $0.7(0.1)$ & $0.7(0.1)$ & $0.7(0.1)$ & $0.9(0.1)$ & $0.9(0.1)$ & $0.8(0.1)$ & $0.7(0.1)$ \\
\hline \multicolumn{9}{|l|}{$P$ value } \\
\hline DH vs. VC & & 0.009 & 0.005 & 0.014 & $<0.00 \mid$ & $<0.001$ & $<0.001$ & $<0.001$ \\
\hline $\mathrm{DH}$ vs. $\mathrm{OH}$ & & $<0.001$ & $<0.001$ & $<0.00 \mid$ & $<0.001$ & $<0.00 \mid$ & $<0.001$ & $<0.00$ । \\
\hline DH vs. SRP & & 0.625 & 0.518 & 0.604 & 0.508 & 0.624 & 0.358 & 0.018 \\
\hline \multicolumn{9}{|l|}{ Study 2} \\
\hline \multicolumn{9}{|l|}{$\mathrm{DH}$} \\
\hline N & 96 & 86 & 84 & 88 & 79 & 80 & 84 & 85 \\
\hline Mean (s.e.) & $5.3(<0.1)$ & $0.8(<0.1)$ & $0.8(0.1)$ & $0.9(0.1)$ & I.I (0.1) & I.I (0.1) & $1.2(0.1)$ & I.I (0.1) \\
\hline \multicolumn{9}{|l|}{ VC } \\
\hline N & 96 & 89 & 87 & 81 & 81 & 81 & 79 & 83 \\
\hline Mean (s.e.) & $5.3(<0.1)$ & $0.5(<0.1)$ & $0.5(0.1)$ & $0.5(0.1)$ & $0.7(0.1)$ & $0.8(0.1)$ & $0.7(0.1)$ & $0.7(0.1)$ \\
\hline \multicolumn{9}{|l|}{$\mathrm{OH}$} \\
\hline N & 94 & 85 & 86 & 89 & 89 & 88 & 85 & 89 \\
\hline Mean (s.e.) & $5.3(<0.1)$ & $0.4(<0.1)$ & $0.5(0.1)$ & $0.6(0.1)$ & $0.7(0.1)$ & $0.7(0.1)$ & $0.7(0.1)$ & $0.7(0.1)$ \\
\hline \multicolumn{9}{|l|}{ SRP } \\
\hline$N$ & 103 & 90 & 91 & 90 & 86 & 90 & 97 & 98 \\
\hline Mean (s.e.) & $5.3(<0.1)$ & $0.9(<0.1)$ & $0.9(0.1)$ & $1.0(0.1)$ & $1.1(0.1)$ & $1.1(0.1)$ & $1.1(0.1)$ & I.I (0.1) \\
\hline \multicolumn{9}{|l|}{$P$ value } \\
\hline DH vs. VC & & $<0.001$ & $<0.00 \mid$ & $<0.001$ & $<0.00 \mid$ & $<0.00 \mid$ & $<0.001$ & $<0.001$ \\
\hline $\mathrm{DH}$ vs. $\mathrm{OH}$ & & $<0.001$ & $<0.001$ & $<0.001$ & $<0.001$ & $<0.001$ & $<0.001$ & $<0.001$ \\
\hline DH vs. SRP & & 0.155 & 0.359 & 0.567 & 0.985 & 0.836 & 0.687 & 0.954 \\
\hline
\end{tabular}

ALG and PD Reduction in Severe Sites (Initial PD $\geq 7 \mathrm{~mm}$ )

Table 5 presents ALG for sites initially $\geq 7 \mathrm{~mm}$ in depth. In both studies, the $\mathrm{DH}$ treatment group is superior to $\mathrm{OH}$ at most timepoints. The DH and SRP groups demonstrate very similar changes throughout the study. VC shows a smaller clinical response than the DH and SRP groups, although the differences are generally not significantly different. The magnitude of ALG in sites $\geq 7 \mathrm{~mm}$ is greater in all treatment groups in both studies than that seen in the moderate sites, and it is somewhat greater than the overall mean changes.

Table 6 presents PD reduction in deeper sites. As with previous analysis in both Study 1 and Study 2, the majority of the change occurred at month 1 , with a small incremental benefit after the second treatment at 


\section{Table 5.}

Gain in Attachment Level (mm) for Initial Probing Depths of $\geq 7 \mathrm{~mm}$

\begin{tabular}{|c|c|c|c|c|c|c|c|c|}
\hline & Baseline & Month I & Month 2 & Month 4 & Month 5 & Month 6 & Month 8 & Month 9 \\
\hline \multicolumn{9}{|l|}{ Study 1} \\
\hline \multicolumn{9}{|l|}{$\mathrm{DH}$} \\
\hline N & 92 & 76 & 73 & 73 & 72 & 70 & 71 & 78 \\
\hline Mean (s.e.) & $7.3(0.2)$ & $0.9(0.1)$ & $0.8(0.1)$ & $0.8(0.1)$ & $0.7(0.1)$ & $0.9(0.1)$ & $0.8(0.1)$ & $0.9(0.1)$ \\
\hline \multicolumn{9}{|l|}{ VC } \\
\hline$N$ & 94 & 85 & 78 & 80 & 74 & 75 & 76 & 80 \\
\hline Mean (s.e.) & $7.3(0.2)$ & $0.7(0.1)$ & $0.7(0.1)$ & $0.8(0.1)$ & $0.6(0.1)$ & $0.8(0.1)$ & $0.6(0.1)$ & $0.6(0.1)$ \\
\hline \multicolumn{9}{|l|}{$\mathrm{OH}$} \\
\hline$N$ & 94 & 83 & 79 & 77 & 72 & 76 & 76 & 81 \\
\hline Mean (s.e.) & $7.4(0.3)$ & $0.6(0.1)$ & $0.5(0.1)$ & $0.4(0.1)$ & $0.4(0.1)$ & $0.5(0.1)$ & $0.5(0.1)$ & $0.4(0.1)$ \\
\hline \multicolumn{9}{|l|}{ SRP } \\
\hline N & 98 & 80 & 87 & 91 & 79 & 79 & 84 & 82 \\
\hline Mean (s.e.) & $7.0(0.2)$ & $0.9(0.1)$ & $0.9(0.1)$ & $0.9(0.1)$ & $1.0(0.1)$ & $1.0(0.1)$ & $1.2(0.1)$ & $1.0(0.1)$ \\
\hline \multicolumn{9}{|l|}{$P$ value } \\
\hline DH vs. VC & & 0.156 & 0.296 & 0.874 & 0.423 & 0.645 & 0.287 & 0.097 \\
\hline $\mathrm{DH}$ vs. $\mathrm{OH}$ & & 0.026 & 0.063 & 0.037 & 0.060 & 0.050 & $0.07 \mid$ & 0.015 \\
\hline DH vs. SRP & & 0.958 & 0.625 & 0.394 & 0.173 & 0.450 & 0.065 & 0.451 \\
\hline \multicolumn{9}{|l|}{ Study 2} \\
\hline \multicolumn{9}{|l|}{ DH } \\
\hline N & 90 & 82 & 81 & 81 & 73 & 73 & 76 & 77 \\
\hline Mean (s.e.) & $7.2(0.3)$ & $0.8(0.1)$ & $0.8(0.1)$ & $0.9(0.1)$ & I.I (0.1) & $1.2(0.1)$ & $1.3(0.1)$ & $1.1(0.1)$ \\
\hline \multicolumn{9}{|l|}{ VC } \\
\hline$N$ & 89 & 82 & 79 & 73 & 75 & 76 & 73 & 76 \\
\hline Mean (s.e.) & $7.3(0.3)$ & $0.8(0.1)$ & $0.6(0.1)$ & $0.7(0.1)$ & $0.8(0.1)$ & $0.9(0.1)$ & $0.9(0.1)$ & $0.9(0.1)$ \\
\hline \multicolumn{9}{|l|}{$\mathrm{OH}$} \\
\hline$N$ & 90 & 82 & 83 & 87 & 86 & 86 & 82 & 86 \\
\hline Mean (s.e.) & $7.1(0.3)$ & $0.7(0.1)$ & $0.6(0.1)$ & $0.8(0.1)$ & $0.8(0.1)$ & $0.8(0.1)$ & $0.7(0.1)$ & $0.8(0.1)$ \\
\hline \multicolumn{9}{|l|}{ SRP } \\
\hline N & 96 & 83 & 85 & 85 & 80 & 83 & 91 & 91 \\
\hline Mean (s.e.) & $7.0(0.2)$ & $0.7(0.1)$ & $0.8(0.1)$ & $0.8(0.1)$ & $0.9(0.1)$ & $0.9(0.1)$ & I.I (0.1) & I.I (0.1) \\
\hline \multicolumn{9}{|l|}{$P$ value } \\
\hline DH vs. VC & & 0.805 & 0.090 & 0.209 & 0.089 & 0.150 & 0.054 & 0.522 \\
\hline $\mathrm{DH}$ vs. $\mathrm{OH}$ & & 0.433 & 0.095 & 0.483 & 0.035 & 0.032 & 0.005 & 0.183 \\
\hline DH vs. SRP & & 0.465 & 0.977 & 0.626 & 0.125 & 0.124 & 0.272 & 0.868 \\
\hline
\end{tabular}

month 4 in the DH and SRP groups. DH treatment was statistically superior $(P \leq 0.05)$ to $\mathrm{OH}$ at all timepoints beginning at month 1 in both studies. DH was superior to VC at all timepoints in Study 2 and at most timepoints in Study 1. DH and SRP showed nearly identical responses throughout both studies. The overall magnitude of the clinical change in all treatment groups was greater in Study 2 compared to Study 1. Changes in the $\mathrm{VC}$ group were generally greater than the $\mathrm{OH}$ group in both studies.

Frequency of Change (Frequency Distribution) ALG and PD Reductions

Table 7 presents the frequency of ALG change for sites evaluated for ALG in both Study 1 and Study 2. Sites that exhibited $a \geq 2 \mathrm{~mm}$ ALG are nearly identical when 


\section{Table 6.}

\section{Reduction in Probing Depth (mm) for Initial Probing Depths of $\geq 7 \mathrm{~mm}$}

\begin{tabular}{|c|c|c|c|c|c|c|c|c|}
\hline & Baseline & Month I & Month 2 & Month 4 & Month 5 & Month 6 & Month 8 & Month 9 \\
\hline \multicolumn{9}{|l|}{ Study I } \\
\hline \multicolumn{9}{|l|}{$\mathrm{DH}$} \\
\hline N & 95 & 79 & 75 & 74 & 74 & 72 & 73 & 80 \\
\hline Mean (s.e.) & $7.5(0.1)$ & $1.3(0.1)$ & $1.3(0.1)$ & $1.3(0.1)$ & $1.5(0.1)$ & $1.5(0.1)$ & $1.5(0.1)$ & $1.6(0.1)$ \\
\hline \multicolumn{9}{|l|}{ VC } \\
\hline N & 94 & 85 & 78 & 80 & 74 & 75 & 76 & 80 \\
\hline Mean (s.e.) & $7.5(0.1)$ & $1.0(0.1)$ & $1.0(0.1)$ & $1.1(0.1)$ & $1.2(0.1)$ & $1.2(0.1)$ & $1.1(0.1)$ & I.I (0.1) \\
\hline \multicolumn{9}{|l|}{$\mathrm{OH}$} \\
\hline N & 95 & 84 & 79 & 77 & 72 & 76 & 76 & 81 \\
\hline Mean (s.e.) & $7.6(0.1)$ & $0.9(0.1)$ & $0.9(0.1)$ & $0.8(0.1)$ & $1.0(0.1)$ & $0.8(0.1)$ & $1.0(0.1)$ & $0.9(0.1)$ \\
\hline \multicolumn{9}{|l|}{ SRP } \\
\hline N & 99 & 80 & 88 & 91 & 80 & 80 & 85 & 83 \\
\hline Mean (s.e.) & $7.6(0.1)$ & $1.5(0.1)$ & $1.4(0.1)$ & $1.5(0.1)$ & $1.6(0.1)$ & $1.7(0.1)$ & $1.6(0.1)$ & $1.5(0.1)$ \\
\hline \multicolumn{9}{|l|}{$P$ value } \\
\hline DH vs. VC & & 0.016 & 0.068 & 0.126 & 0.014 & 0.058 & 0.014 & 0.002 \\
\hline $\mathrm{DH}$ vs. $\mathrm{OH}$ & & 0.001 & 0.008 & 0.002 & $<0.001$ & $<0.001$ & 0.001 & $<0.001$ \\
\hline DH vs. SRP & & 0.341 & 0.244 & 0.332 & 0.293 & 0.260 & 0.783 & 0.569 \\
\hline \multicolumn{9}{|l|}{ Study 2} \\
\hline \multicolumn{9}{|l|}{$\mathrm{DH}$} \\
\hline N & 96 & 86 & 84 & 87 & 77 & 78 & 82 & 83 \\
\hline Mean (s.e.) & $7.6(0.1)$ & $1.4(0.1)$ & $1.5(0.1)$ & $1.4(0.1)$ & $1.9(0.1)$ & $1.8(0.1)$ & $1.9(0.1)$ & $1.9(0.1)$ \\
\hline \multicolumn{9}{|l|}{ VC } \\
\hline N & 94 & 87 & 84 & 78 & 79 & 79 & 78 & 81 \\
\hline Mean (s.e.) & $7.6(0.1)$ & $1.0(0.1)$ & $0.9(0.1)$ & $1.1(0.1)$ & $1.3(0.1)$ & $1.4(0.1)$ & $1.4(0.1)$ & $1.6(0.1)$ \\
\hline \multicolumn{9}{|l|}{$\mathrm{OH}$} \\
\hline N & 93 & 84 & 85 & 88 & 88 & 87 & 84 & 88 \\
\hline Mean (s.e.) & $7.5(0.1)$ & $1.0(0.1)$ & $1.1(0.1)$ & $1.1(0.1)$ & $1.3(0.1)$ & $1.3(0.1)$ & $1.3(0.1)$ & $1.3(0.1)$ \\
\hline \multicolumn{9}{|l|}{ SRP } \\
\hline N & 103 & 90 & 91 & 89 & 85 & 89 & 96 & 97 \\
\hline Mean (s.e.) & $7.5(0.1)$ & $1.4(0.1)$ & $1.6(0.1)$ & $1.5(0.1)$ & $1.8(0.1)$ & $1.7(0.1)$ & $1.8(0.1)$ & $1.8(0.1)$ \\
\hline \multicolumn{9}{|l|}{$P$ value } \\
\hline DH vs. VC & & 0.007 & $<0.001$ & 0.051 & $<0.001$ & 0.007 & 0.001 & 0.050 \\
\hline $\mathrm{DH}$ vs. $\mathrm{OH}$ & & 0.005 & 0.007 & 0.040 & $<0.001$ & $<0.001$ & $<0.001$ & $<0.001$ \\
\hline DH vs. SRP & & 0.809 & 0.327 & 0.831 & 0.762 & 0.512 & 0.558 & 0.489 \\
\hline
\end{tabular}

$\mathrm{DH}$ and SRP groups are compared in both studies. The VC group generally shows a frequency of $6 \%$ to $10 \%$ less than these groups, and the $\mathrm{OH}$ group shows a frequency somewhat less than the VC group. In Study 1 at month $9,29 \%$ of treated sites in the $\mathrm{DH}$ group and $27 \%$ of treated sites in the SRP group showed a $\geq 2$ mm ALG. In Study 2, 31\% of treated sites in the DH group and $34 \%$ in the SRP group showed $a \geq 2$ mm ALG.
Table 8 shows the frequency of PD change for all treated sites. When evaluating sites that showed $\geq 2 \mathrm{~mm}$ PD reduction at month 9, the DH and SRP groups showed similar responses, with $32 \%$ of the DH sites and $31 \%$ of the SRP sites showing this change in Study 1, and $41 \%$ and $43 \%$ in Study 2, respectively. The VC group showed a 10\% to $15 \%$ less change of this magnitude in the 2 studies; the $\mathrm{OH}$ group showed a $15 \%$ to $20 \%$ less change. 


\section{Table 7.}

Frequency of Attachment Level Change by Gain, No Change, and Loss

\begin{tabular}{|c|c|c|c|c|c|c|c|c|c|c|c|c|c|}
\hline & & & $\mathrm{DH}$ & & & VC & & & $\mathrm{OH}$ & & & SRP & \\
\hline & & 4 & 6 & 9 & 4 & 6 & 9 & 4 & 6 & 9 & 4 & 6 & 9 \\
\hline & & & & & & & & & & & & & \\
\hline Gain & & & & & & & & & & & & & \\
\hline$\geq 1 \mathrm{~mm}$ & Sites & 369 & 355 & 402 & 357 & 350 & 358 & 303 & 315 & 304 & 452 & 408 & 420 \\
\hline & $\%$ & 57 & 59 & 60 & 53 & 55 & 54 & 48 & 50 & 47 & 59 & 62 & 60 \\
\hline$\geq 2 \mathrm{~mm}$ & Sites & 173 & 162 & 190 & 152 & 153 & 145 & 110 & 130 & 101 & 205 & 187 & 189 \\
\hline & $\%$ & 27 & 27 & 29 & 23 & 24 & 22 & 17 & 21 & 16 & 27 & 28 & 27 \\
\hline$\geq 3 \mathrm{~mm}$ & Sites & 69 & 64 & 73 & 46 & 45 & 43 & 27 & 39 & 30 & 59 & 57 & 56 \\
\hline & $\%$ & 11 & 11 & 11 & 7 & 7 & 7 & 4 & 6 & 5 & 8 & 9 & 8 \\
\hline No Change & & & & & & & & & & & & & \\
\hline $0 \mathrm{~mm}$ & Sites & 116 & 116 & 126 & 137 & 104 & 97 & 132 & 125 & 135 & 141 & 96 & 115 \\
\hline & $\%$ & 18 & 19 & 19 & 20 & 16 & 15 & 21 & 20 & 21 & 18 & 14 & 17 \\
\hline Loss & & & & & & & & & & & & & \\
\hline$\geq 1 \mathrm{~mm}$ & Sites & 161 & 129 & 137 & 176 & 183 & 202 & 194 & 193 & 211 & 175 & 159 & 160 \\
\hline & $\%$ & 25 & 22 & 21 & 26 & 29 & 31 & 31 & 30 & 32 & 23 & 24 & 23 \\
\hline$\geq 2 \mathrm{~mm}$ & Sites & 32 & 40 & 37 & 56 & 61 & 65 & 48 & 61 & 71 & 53 & 43 & 46 \\
\hline & $\%$ & 5 & 7 & 6 & 8 & 10 & 10 & 8 & 10 & 11 & 7 & 6 & 7 \\
\hline$\geq 3 \mathrm{~mm}$ & Sites & 9 & 15 & 10 & 19 & 23 & 24 & 15 & 16 & 19 & 9 & 5 & 10 \\
\hline & $\%$ & I & 3 & 2 & 3 & 4 & 4 & 2 & 3 & 3 & I & I & I \\
\hline Total Sites & & 646 & 600 & 665 & 670 & 637 & 657 & 629 & 633 & 650 & 768 & 663 & 695 \\
\hline & & & & & & & & & & & & & \\
\hline Gain & & & & & & & & & & & & & \\
\hline$\geq 1 \mathrm{~mm}$ & Sites & 460 & 451 & 465 & 349 & 371 & 375 & 390 & 415 & 423 & 457 & 502 & 549 \\
\hline & $\%$ & 61 & 67 & 66 & 52 & 56 & 56 & 52 & 56 & 57 & 61 & 65 & 67 \\
\hline$\geq 2 \mathrm{~mm}$ & Sites & 198 & 208 & 222 & 122 & 155 & 161 & 160 & 171 & 154 & 199 & 242 & 278 \\
\hline & $\%$ & 26 & 31 & 31 & 18 & 23 & 24 & 21 & 23 & 21 & 27 & 31 & 34 \\
\hline$\geq 3 \mathrm{~mm}$ & Sites & 71 & 62 & 75 & 25 & 49 & 38 & 56 & 45 & 52 & 58 & 68 & 92 \\
\hline & $\%$ & 9 & 9 & 11 & 4 & 7 & 6 & 7 & 6 & 7 & 8 & 9 & 11 \\
\hline No Change & & & & & & & & & & & & & \\
\hline $0 \mathrm{~mm}$ & Sites & 146 & 110 & 131 & 142 & 120 & 129 & 179 & 153 & 155 & 143 & 111 & 123 \\
\hline & $\%$ & 19 & 16 & 19 & 21 & 18 & 19 & 24 & 21 & 21 & 19 & 14 & 15 \\
\hline Loss & & & & & & & & & & & & & \\
\hline$\geq 1 \mathrm{~mm}$ & Sites & 150 & 109 & 112 & 178 & 175 & 169 & 178 & 168 & 158 & 149 & 157 & 149 \\
\hline & $\%$ & 20 & 16 & 16 & 27 & 26 & 25 & 24 & 23 & 21 & 20 & 20 & 18 \\
\hline$\geq 2 \mathrm{~mm}$ & Sites & 28 & 33 & 29 & 47 & 43 & 44 & 47 & 36 & 44 & 47 & 38 & 37 \\
\hline & $\%$ & 4 & 5 & 4 & 7 & 6 & 7 & 6 & 5 & 6 & 6 & 5 & 5 \\
\hline$\geq 3 \mathrm{~mm}$ & Sites & 3 & 6 & 8 & 13 & 12 & 10 & 12 & 8 & 10 & 14 & 8 & 9 \\
\hline & $\%$ & $<1$ & I & I & 2 & 2 & I & 2 & I & I & 2 & I & I \\
\hline Total Sites & & 756 & 670 & 708 & 669 & 666 & 673 & 747 & 736 & 7.6 & 749 & 770 & 821 \\
\hline
\end{tabular}

\section{Plaque Scores}

Baseline plaque scores ${ }^{18}$ for each treatment group in Study 1 were: $\mathrm{DH}=1.0 ; \mathrm{VC}=1.0 ; \mathrm{OH}=1.1 ; \mathrm{SRP}=1.1$. Average reductions for the treatment groups over the course of Study 1 were: $\mathrm{DH}=0.13 ; \mathrm{VC}=0.07 ; \mathrm{OH}=0.16$; $\mathrm{SRP}=0.20$. In Study 2, baseline scores were: $\mathrm{DH}=1.0$; $\mathrm{VC}=1.0 ; \mathrm{OH}=1.1 ; \mathrm{SRP}=1.1$. Average reductions for the treatment groups during the study were: $\mathrm{DH}=0.16$; $\mathrm{VC}=0.07 ; \mathrm{OH}=0.27 ; \mathrm{SRP}=0.14$.

\section{Safety}

In Study 1, there were $54(\mathrm{DH}=17 ; \mathrm{VC}=24 ; \mathrm{OH}=1$; $\mathrm{SRP}=12)$ treatment-related adverse events reported (defined as probably or possibly related to treatment). 
Table 8.

Frequency of Probing Depth Change by Reduction, No Change, and Gain

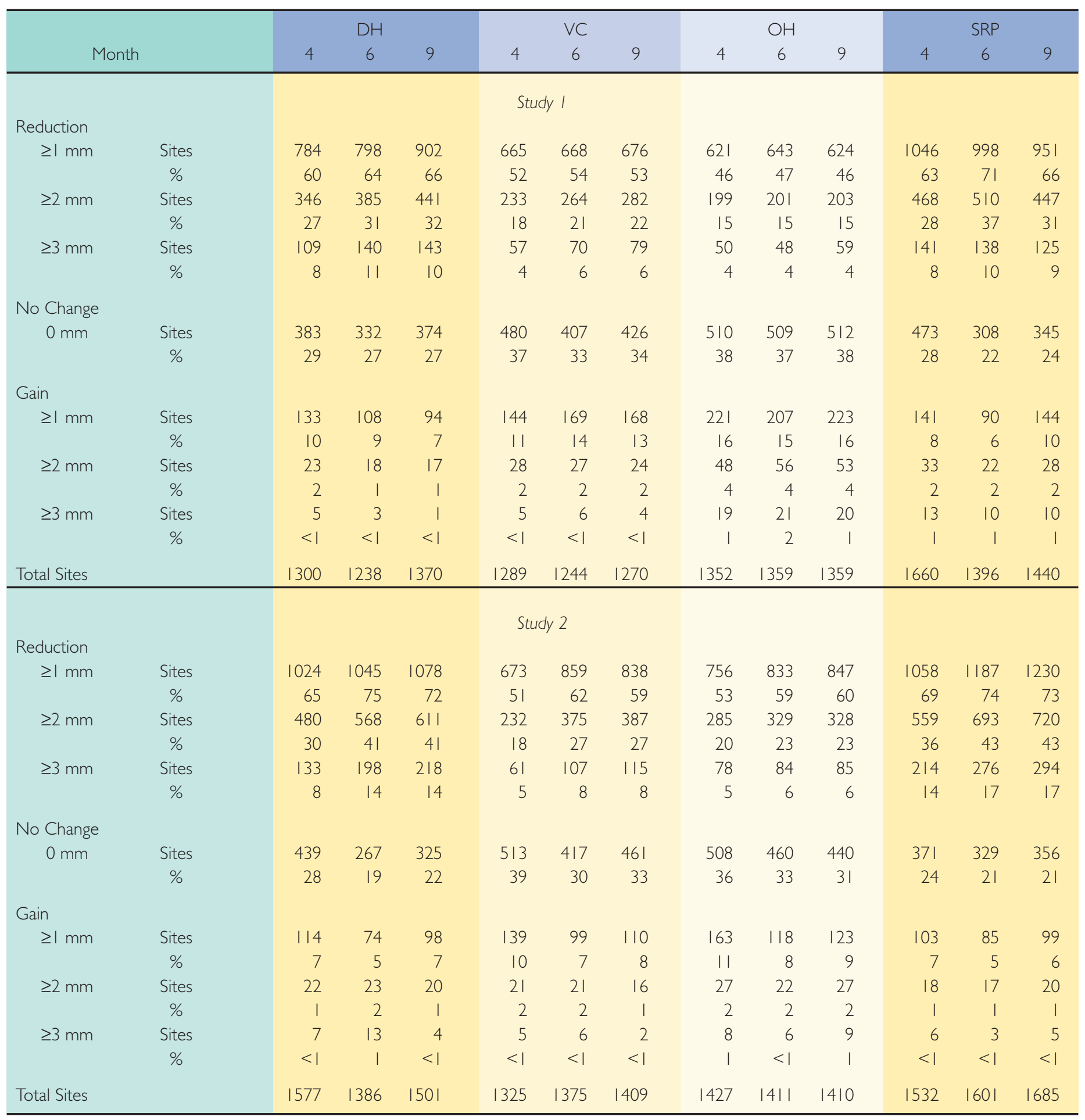

A large majority of these events were related to mild or moderate gingival soreness following treatment. Two subjects withdrew from the study due to treatmentrelated adverse events. Both were in the VC treatment group. One subject withdrew because of gingival soreness resulting from VC placement. The second subject experienced a mild erythematous reaction and a burning sensation at the site of placement. This reflects an incidence of this event of $<1 \%$ of the subjects treated with VC.

Treated sites were exited when an attachment loss $\geq 2 \mathrm{~mm}$ from baseline was detected. Sixty-five subjects 
(16\%) had treated teeth exited from analysis. The percentage of subjects with exited treated sites relative to treatment group was $13 \%$ for $\mathrm{DH}, 14 \%$ for VC, $19 \%$ for $\mathrm{OH}$, and $17 \%$ for SRP.

In Study 2, there were $80(\mathrm{DH}=21 ; \mathrm{VC}=27 ; \mathrm{OH}=9$; $\mathrm{SRP}=23$ ) treatment-related adverse events reported. Again, a large majority of these events were related to mild or moderate gingival soreness following treatment. One subject withdrew from the study due to a treatment-related adverse event. This subject was in the VC treatment group and apparently experienced an exacerbation of an undiagnosed periodontic/endodontic lesion at the time of VC placement.

Fifty-four subjects (13\%) had treated teeth exited for the previously described reason. The percentage of subjects with exited treated sites relative to treatment group was $15 \%$ for $\mathrm{DH}, 16 \%$ for $\mathrm{VC}, 13 \%$ for $\mathrm{OH}$, and $8 \%$ for SRP.

No subjects in either study experienced an outbreak of oral candidiasis.

\section{DISCUSSION}

Both multi-center trials show clinically similar results for PD reduction and ALG when the DH treatment is compared to SRP. The DH treatment groups did not receive mechanical treatment other than $\mathrm{OH}$ throughout the study. The SRP arm was not controlled for time of instrumentation or use of local anesthesia as has been done in previous trials. ${ }^{21,22}$ Therapists used local anesthesia at the patients' request and performed SRP until the root surfaces were hard and smooth to an explorer. These data demonstrate that in these large subject populations, 2 applications of DH 4 months apart were as effective as repeated SRP treatments 4 months apart in reducing the clinical signs of periodontitis. Frequency distributions demonstrated the same pattern of similar effectiveness. Changes associated with the SRP groups are similar to previously described changes following definitive SRP of pockets with this initial depth. ${ }^{3,23}$ It should be noted that the duration of this study was 9 months and that longer observation periods may have indicated the need for mechanical debridement of the pockets.

Results of both trials demonstrate superiority for the $\mathrm{DH}$ treatment group compared to $\mathrm{OH}$ and VC treatment groups. This is true for overall mean PD reduction and ALG and is apparent when sites are grouped according to initial probing depth in moderate ( 5 to $6 \mathrm{~mm}$ ) and deep $(\geq 7 \mathrm{~mm})$ site data sets. Frequency distributions also demonstrate the same advantage for the $\mathrm{DH}$ group. The activity of the VC treatment group was generally similar to the $\mathrm{OH}$ group with some additional benefit particularly in deeper sites. This was most noticeable when ALG for sites $\geq 7 \mathrm{~mm}$ was compared. This supports previous suggestions that this vehicle has some inherent activity on its own. ${ }^{12,24}$
Most of the clinical changes resulted from baseline treatment and occurred over the first few months. There were small incremental changes following the repeated treatment at month 4 , especially in the DH and SRP treatment groups, although these improvements were much less than the changes following the initial treatment. Other studies have assessed subgingival antimicrobial treatment without concomitant SRP as well as adjunctive to SRP. ${ }^{10}$ Results of this trial compare favorably with these trials.

The safety profile in the DH treatment group showed a very low incidence of treatment-related adverse events. The most common event was a mild gingival soreness after placement. This usually resolved within a day or two. One subject in Study 1 experienced symptoms suggesting a localized allergic response associated with placement of the VC. This resolved shortly after removal and represents an overall incidence of $<1 \%$ of treated subjects from the 2 studies. No subjects from either study experienced difficulties with oral candidiasis. Use of the DH product does not appear to place subjects at additional risk beyond that experienced with traditional periodontal therapy.

To be effective in vivo, a pharmacologic agent must meet 3 described criteria: 1) reach the site of action; 2) be maintained there in a sufficient concentration; and 3) be maintained long enough for the intended effect to occur. ${ }^{25}$ In treating periodontitis with local antiinfective agents, the delivery system for the active agent is particularly important because of the turnover of gingival fluid in the periodontal pocket, and its ability to flush these agents from the pocket. ${ }^{26}$ Delivery systems have been categorized as sustained or controlled devices based on how long the delivered agent is available. Sustained devices generally provide delivery for less than 24 hours. Controlled delivery devices should provide delivery for more than one day. ${ }^{27,28}$ Pharmacokinetic evaluation of doxycycline delivery to treated sites indicates that this delivery system functions as a controlled delivery device with minimum inhibitory concentrations $\left(\mathrm{MIC}_{90}\right)$ of doxycycline well above the $\mathrm{MIC}_{90}$ for suspected periodontal pathogens for 7 to 10 days. ${ }^{29}$ The advantages of controlled delivery devices are described as: 1) better subject compliance; 2) enhanced or improved pharmacokinetic response; 3 ) a greater advantage in positioning the active agent in proximity to the disease; and 4) delivery of a lower total dose of drug at a more controlled concentration. ${ }^{25}$ Prolonged delivery at high concentrations may be particularly important in periodontitis-involved sites because subgingival plaque tends to organize as a biofilm. Antimicrobial action on bacteria organized in a biofilm may require concentrations of active agents that are several times higher than those effective against bacteria grown on agar plates. ${ }^{30,31}$

Subsequent research reports will present analyses 
for smokers versus non-smokers, response of subjects related to periodontal treatment history, and response of furcation and non-furcation sites.

In summary, data from these 2 multi-center trials demonstrate: 1) DH treatment and SRP treatment result in clinically equivalent results in both ALG and PD reduction in both studies; 2) DH treatment is clearly superior to $\mathrm{OH}$ and VC treatments in terms of ALG and PD reduction in both studies; and 3) DH treatment presents with a very benign safety profile. Subjects are not at any additional risk following this treatment compared to standard periodontal therapies.

\section{ACKNOWLEDGMENTS}

Dr. Garrett is Vice President of Clinical Research, Dr. Southard is President and Chief Scientific Officer, and Ms. Duke was formerly Manager of Biostatistics at Atrix Laboratories. We wish to specifically acknowledge the contributions of our co-author, Dr. Bradley Beiswanger who died in 1998, and his very capable research staff. We also gratefully recognize Ms. Michelle Parmelee for manuscript preparation; Susan Gould, Sherry Palmateer, Cindy Croissant, Jean Megna, Kimberly Buda, and Wes Ortolano for study coordination, monitoring, and management; IBAH in Blue Bell, Pennsylvania for data management services; and Barb Jones for quality assurance of data summaries. This study was supported by Atrix Laboratories, Inc., Fort Collins, Colorado.

\section{REFERENCES}

1. Zambon JJ. Periodontal diseases: Microbial factors. Ann Periodontol 1996;1:879-925.

2. Offenbacher S. Periodontal diseases: Pathogenesis. Ann Periodontol 1996;1:821-878.

3. Cobb CM. Non-surgical pocket therapy: Mechanical. Ann Periodontol 1996;1:443-490.

4. Palcanis KG. Surgical pocket therapy. Ann Periodontol 1996;1:589-617.

5. Garrett S. Periodontal regeneration around natural teeth. Ann Periodontol 1996;1:621-666.

6. Wennström JL. Mucogingival therapy. Ann Periodontol 1996;1:671-701.

7. Goodson JM, Haffajee AD, Socransky SS. Periodontal therapy by local drug delivery of tetracycline. J Clin Periodontol 1979;6:83-92.

8. Fiorellini JP, Packet DWG. The potential role of controlledrelease delivery systems for chemotherapeutic agents in periodontics. Curr Opin Dent 1992; 2:63-79.

9. Kornman KS. Controlled-release local delivery antimicrobials in periodontics: Prospects for the future. $J$ Periodontol 1993;64:782-791.

10. Drisko CL. Non-surgical pocket therapy: Pharmacotherapeutics. Ann Periodontol 1996;1:491-566.

11. Polson AM, Southard GL, Dunn RL, et. al. Periodontal pocket treatment in beagle dogs using subgingival doxycycline from a biodegradable system. I. Initial clinical responses. J Periodontol 1996;67:1176-1184.

12. Polson AM, Garrett S, Stoller NH, et al. Multi-center comparative evaluation of subgingivally delivered sanguinarine and doxycycline in the treatment of periodontitis. II. Clinical results. J Periodontol 1997;68:119-126.
13. Polson AM, Garrett S, Stoller NH, et al. Multi-center comparative evaluation of subgingivally delivered sanguinarine and doxycycline in the treatment of periodontitis. I. Study design, procedure, and management. J Periodontol 1997;68:110-118.

14. Title 21, Code of Federal Regulations Part 56: Institutional Review Boards. U.S. Government Printing Office; 1995.

15. Title 21, Code of Federal Regulations Part 50: Institutional Review Boards. U.S. Government Printing Office;1995.

16. Ramfjord SP. The periodontal index (PDI). J Periodontol 1967;38:602-610.

17. Polson AM, Southard GL, Dunn RL, et al. Initial study of guided tissue regeneration in Class II furcation defects after use of a biodegradable barrier. Int $J$ Periodontics Restorative Dent 1995;15:43-55.

18. Silness J, Löe H. Periodontal disease in pregnancy. II. Correlation between oral hygiene and periodontal condition. Acta Odontol Scand 1964;22:121-135.

19. Laster L. The effect of subsampling sites within patients. $J$ Periodont Res 1985;20:91-96.

20. Goodson JM, Cugini MA, Kent RL, et al. Multi-center evaluation of tetracycline fiber therapy. II. Clinical response. J Periodont Res 1991;26:371-379.

21. van Steenberghe D, Bercy P, Kohl J, et al. Subgingival minocycline hydrochloride ointment in moderate to severe chronic adult periodontitis: A randomized, doubleblind, vehicle-controlled multi-center study. J Periodontol 1993;64:637-644.

22. Soskolne WA, Heasman PA, Stabholz A, et al. Sustained local delivery of chlorhexidine in the treatment of periodontitis: A multi-center study. J Periodontol 1997;68:32-38.

23. Greenstein G. Periodontal response to mechanical nonsurgical therapy: A review. J Periodontol 1992;63:118130.

24. Polson AM, Stoller NH, Hanes PJ, et al. Two multi-center trials assessing the clinical efficacy of $5 \%$ sanguinarine in a biodegradable drug delivery system. $J$ Clin Periodontol 1996;23:782-788.

25. Goodson J. Pharmacokinetic principles controlling efficacy of oral therapy. J Dent Res 1989;68(Spec. Issue): 1625-1632.

26. Oosterwaal PJ, Mikx FHM, Rennggli HH. Clearance of a topically applied fluorescein gel from periodontal pockets. J Clin Periodontol 1990;17:129-137.

27. Langer R, Peppas N. Present and future applications of biomaterials in controlled drug delivery systems. Biomaterials 1981;2:201-214.

28. Langer R. New methods of drug delivery. Science 1990;249:1527-1533.

29. Stoller NH, Johnson LR, Trapnell S, Harrold CQ, Garrett $\mathrm{S}$. The pharmokinetic profile of a biodegradable controlled-release delivery system containing doxycycline compared to systemically delivered doxycycline in gingival crevicular fluid, saliva, and serum. J Periodontol 1998;69:1085-1091.

30. Anwar H, Strap J, Costerton J. Establishment of aging biofilms: Possible mechanism of bacterial resistance to antimicrobial therapy. Antimicrob Agents Chemother 1992;36:1347-1351.

31. Brown M, Gilbert P. Sensitivity of biofilms to antimicrobial agents. J Appl Bacteriol 1993; 74(Suppl.):87S-97S.

Send reprint requests to: Dr. Steven Garrett, Atrix Laboratories, Inc., 2579 Midpoint Drive, Fort Collins, CO 80525. Fax: 970/482-9735.

Accepted for publication September 25, 1998. 